acet. cantharides, half an ounce : $\mathrm{mix}$, and make into a lotion; a piece of lint moistened with the lotion to be applied for ten minutes night and morning to the chest. Compound infusion of roses, six ounces; dilute sulphuric acid, half a drachm; ipecacuanha wine, one drachm; tincture of digitalis, one drachm and a half: mix, and take two spoonfuls every fourth hour.

July 16th. - Weight to-day, 7 st. $4 \frac{1}{1 b s}$. Has had no return of hrmoptysis. Take half an ounce of cod-liver oil twice a day. August 7th. - Chest in the same condition, there still being dulness, \&c.; weight, 7 st. $7 \frac{1}{2} \mathrm{lbs}$. Take an ounce of cod-liver oil twice a day. Advised removal to a milder air.

October 4th. - Is in every respect much improved, and has continued the oil to the present date; weight, 8 st. 5 lbs. Became eventually quite well, and continues so.

CASE 26. - Miss H. C- aged thirty. Elder sister died of phthisis. June 23rd, 1849. A most delicate-looking person, and a good deal emaciated. Is much subject to dyspepsia, and had a very obstimate bronchitic attack last winter; frequent cough, with but little expectoration; tongue furred and slimylooking; slight but evident deficiency of resonance below right clavicle, as compared with the other side; respiration coarse; sound of expiration distinct; mucous rhonchus on left sicle; has frequent subclavian pain on right side. For these symptoms, blistering, expectorants, and attention to the condition of the digestive organs, were perseveringly tried.

July ilth. - Somewhat improved in general health, but extremely feeble and much emaciated; has suffered from profuse night sweats of late; bowels regular; cough troublesome; expectoration muco-purulent, but by no means copious; pulse 80 ; dulness of resonance, \&c., as before; bronchophony in right apex. To have animal food and a glass of bitter ale for dinner. To take two drachms of cod-liver oil three times a day.

22nd. - Is already improved both in strength and appetite; cough diminished. The dose of oil to be doubled.

26 th. - Has retrograded; digestive organs much deranged, with loss of appetite and nausea; pulse 100; slight chilliness in the forenoons, succeeded by fever; night sweats; tongue much furred; cough increased. Ordered, bicarbonate of soda, one scruple; water, one ounce; syrup, one drachm; dilute hydrocyanic acid, three minims: $m i x$ and take every four hours, with half an onnce of lemon-juice in a state of effervescence. Continue the cod-liver oil. Take of mercury pill, three grains; compound rhubarb pill, five grains ; extract of hyoscyamus, three grains: make into two pills, to be taken at bed-time.

August 10th. - Has appeared to be improving for the last ten days, but to-day I find a return of hectic, with increase of congh, and extreme debility; emaciation increasing pulse 110 , small and thready. In addition to the night sweats, from which she has suffered for some weeks, there is now a tendency to diarrhcea; expectoration more copious; right side of chest less expansible than left; evident flattening below right clavicle; cavernous respiration; pectoriloquy.-Evening Pulse 130; sliin hot and dry. Ordered, infusion of cusparia, six ounces; bicarbonate of soda, two scruples; tincture of cinnamon, three drachms; tincture of opium, twelve minims mix, and take one ounce three times a day.

After remaining almost stationary for.some days, the hectic, night sweats, \&c., still going on, and the pulse being rarely below 120 at the time of my daily visit, she began about the 18 th to improve; the pulse fell to 100 , and on the 21 st to 90 .

21st.-Ordered, citrate of quinine and iron, five grains; cinnamon water, one ounce: mix, and take twice a day. Continue the cod-liver oil. Advised her removal to a sheltered, dry situation a few miles in the country.

September 11th.-Much improved; pulse 80 ; no rigors or hectic; appetite and digestion better; is able to walk out daily; expectoration diminished; weight 7 st. $7 \mathrm{lbs}$.

October 9 th. - Has steadily proceeded with the cod-liver oil and chalybeate. Cough and expectoration very much better right side of chest decidedly flattened, and less expansive than left; pectoriloquy and cavernous breathing, both singularly distinct; weight $7 \mathrm{st} .12 \mathrm{lbs}$. Continue the cod-liver oil.

Having continued to improve steadily, though slowly, until the end of October, I then advised her to winter in Devonshire. She went there early in November, and continued taking the cod-liver oil till spring.

March 14th, 1849. - Reports herself as quite well, and able to walk two or three miles a day; is free from cough and expectsration, and weighs 8 st. 13lbs. I saw her again in the summer of 1850 , after she had spent two winters in Devonshire. She appeared perfectly well, and continues so at the present time.

\section{ON A CASE OF \\ WOUND OF THE VAGINA, WITH SEVERE HEMORRHAGE.}

By ROBERT FUWLER, M.D. EDiv.

ON the morning of Feb. 23rd, 1851, a medical man in the neighbourhood called to speak to me respecting a case he had been attending since ten o'clock the night previous. He had sent the friends of the patient to the relieving officer to obtain an order for my attendance, but expressed a wish that I would go with him immediately, as the woman was in great danger, on account of profuse hemorrhage from (what he supposed) a wound of the rectum. I directly (half-past ten A.M.) accompanied him, and found the woman perfectly blanched from loss of blood; the lips were quite pallid, the whole surface of body completely cold; pupils dilated; no pulse at the wrist, but the brachials beat feebly. It was with difficulty she could be roused from her lethargy, and when she spoke it was in a scarcely audible whisper. The bleeding had then ceased. On separating the buttocks, I could detect no external wound; and on examining the rectum digitally, the finger on withdrawal was quite free from any stain of blood. The source of the hremorrhage was therefore still undiscovered. On separating the labia, I soon found that I was on the track of the wound, for the mucous membrane of the vulva, which was completely blanched, was quite moist with blood, which adhered in dried clots to the capillary appendices exterior. On searching further internally, my finger removed a small clot, and out gushed a dark-coloured stream (not in jets) of blood about the size of a crow-quill. Pressure by the finger immediately stopped it, and on examining as carefully as I could, I perceived that the stream came from a jagged wound about the size of a sixpence, at the junction of the superior and right lateral walls of the vagina, to the right, and just above the level, of the meatus uxinarius. A graduated compress of lint dipped in cold water was now applied, and kept in the vagina by two towels used as a $\mathbf{T}$ bandage. Sulphuric acid, twenty-five minims in water, every three hours; brandy, half an ounce, in cold water, every hour; all liquids to be given quite cold; hot bottles to the feet.

I now learnt that at nine o'clock the night previous, whilst at her brother's, in Lambeth-hill, Doctor's-commons, she had occasion to go to the out-door privy, and, in the act of sitting down, she came with full force on the upright wooden handle (having a blunted point) of the cover, which happened to be on. Without mentioning it to her brother, she walked more than a mile to her mother's house, in this parish. Bleeding continued from the lower part of her person the whole way, causing her to feel very faint, and compelling her to lean frequently against the walls of the houses. On her arrival, her whole under garments were completely saturated with blood.

The medical man, at a quarter-past ten P.M., found her in a complete state of collapse; no pulse either at the radials or brachials. He ordered hot bottles to her feet, and gave her hot brandy and water. She was extremely restless the whole night, the blood streaming from her whenever she got out of bed (which she would do) to pass urine.

23rd.-One P.M.: No bleeding; pulse just perceptible at wrist. - Five P.M. : Surface of body wamer, and says she feels better. Stomach rejects all fiuids, which were directed to be given in very small quantities.-Nine P.Mr.: Radial pulse stronger; body warmer; sickness better. Catheter drew of six ounces of clear urine. On readjusting plugs, slight bleeding occuried. Elastic catheter kept in bladder.

24th. - Eleven A.M.: Better; body warmer; sickness abated; tongue very foul; pulse 120, stronger. Urine dribbled away all night, causing her great pain from soaking the lint. Ten P.M.: Voice stronger. Discontinued elastic catheter, desiring her to retain urine. Wound has a superficial slough.

25th.-Sore cleaning, and inclined to granulate. Cnable to hold urine.

From this date she continued to improve, the sore healing nicely under a dressing of dry lint only, its progress being no doubt slightly retarded by the irritating contact of the urine, which for some days she was unable to retain during the short intervals between my visits. Slight rigors occurred on the 1st of March, but subsided after a calomel and jalap purge, followed by saline mixture.

March 8th. - Wound quite healed. Complains of anxmic headache. Take one grain of sulphate of iron in one ounce of water, three times a day.

23rd. - I accidently met her, and she told me that she had 
had a small abscess on the labium, externally, which was now well. She complained of frequent desire to make water, with pain on doing so, and inability to retain the urine long. She had also a bearing down pain, but no prolapsus uteri. I had no opportunity of examining the condition of the vagina, as to whether there was any prolapse of its walls, or hernial tumour, or uterine prolapse, in its cavity.

I have brought this case forward on account of the rarity of the curious accident which was so nearly proving fatal; and also as an instance of the wonderful rallying powers of Nature after severe losses of blood. The source of the hæmorrhage must either have been from the extreme end of the pudic vein itself; which, in the position of the wound, might possibly be injured by a force compressing it against the pubic arch; or, if not from it, from one of the many veins which surround the vagina in a plexiform manner, previous to terminating in the branches of the internal iliac.

Bishopsgate-street Without, December, 1854,

\section{Amedical Sorítíes.}

\section{HA R VEIAN SOCIETY.}

ThURSDAY, DeCEMBER $7 \mathrm{TH}, 1854$.

Mr. Coulson, President, in the Chair.

\section{Mr. URe mentioned the particulars of a case of} COMPOUND FRACTURE OF THE LEG,

which had been under his care in St. Mary's Hospital. A young and healthy-looking man, twenty-eight years of age, was brought into the hospital on the 24th of July, 1854, having shortly beforehand sustained a compound comminuted fracture of the right leg. About three inches above the instep was an irregular gaping wound, nearly two inches long and one inch broad, from which there was a discharge of blood. On gently introducing the finger, it was ascertained that the tibia was broken obliquely about its lower third, and lying bare in the wound; while the fibula was shattered an inch and a-half higher up. For the space of upwards of four inches above the wound, the integuments were completely separated from the subjacent structures. The accident was caused by the fall of a heap of clay and rubbish, weighing eight tons, upon the limb, while the man was standing with one leg before the other. When Mr. Ure saw the patient, not long after admission, his countenance was good; pulse 108 , soft; surface of the body natural; he did not complain of pain. The prominent surgical features of the case were, comminuted fracture of both bones of the leg, a bleeding wound communicating with the fracture, and extensive separation of the integument from its cellular connexions. The hæmorrhage was stanched by the introduction into the wound of a dossil of lint, soaked in a solution of perchloride of iron. Taking into consideration the age of the individual, the apparent soundness of his constitution, and the fact that the hæmorrhage had been stopped, $\mathrm{Mr}$. Ure determined to use his best endeavours to save the limb. The fractured ends of the bone having been carefully adjusted, and a bandage applied, so as to maintain the loosened integument in apposition with the subjacent parts, the limb was placed on a double-inclined splint. The patient was ordered ordinary diet, with four ounces of sherry daily; ice to allay thirst; and an opiate at bed-time. On the 27 th of July, as sloughing had commenced in the part, he was allowed, besides the wine, a pint of porter every day. On the 3lst of July, the sloughing process had ceased, as shown by a limitary line round the margin of the wound; the surrounding integument appeared natural. The patient felt well in health; his countenance was cheerful; appetite good; sleep sound; skin cool; tongue clean; pulse soft, 120 in the minute. On the 3rd of August, about a square inch of denuded bone was visible in the cavity of the wound; the discharge from the latter was serous. The process of granulation was advancing steadily from the circumference towards the centre. By the 9 th of August, the wound was nearly covered with granulations. The general health of the patient was satisfactory. The limb was placed in a suspensory fracture apparatus. On the following afternoon, the man was seized with acute pain of the right side, aggravated on full inspiration; the tongue was brown, but moist; there was urgent thirst; hot skin; the pulse was 108 , full; the pain became so severe that night as to prevent sleep; the surface of the wound was rather dry and glazed. This attack yielded to the application of leeches and cupping, followed by the exhibition of James's powder, so that in two days the man was convalescent. By the 24th of the same month, the sore was reduced to one-third of its original dimensions, and looked healthy. A month later, the sore was nearly cicatrized. The limb was encased in pasteboard with starched bandages, a small aperture being left, to permit the escape of any discharge. Before ten days were over, the man could move about the ward with the aid of crutches. About this period, a splinter of bone, of irregnlar shape, not above half an inch by a quarter of an inch in size, and half a line thick, exfoliated; after which the part rapidly healed. $\mathrm{He}$ left the hospital cured on the 2nd of November last. Mr. Ure expressed his conviction, that had the posterior tibial artery been wounded in this case, the limb could not have been saved. He adverted to the fact of the minute extent of exfoliation. Considering how much of the surface of the tibia had been laid bare, he deemed it a most fortunate circumstance that, within little more than three months after the receipt of a serious injury of this nature, the man was enjoying good health, and able to move about with tolerable ease.

Mr. WeEdon Cooke exhibited a specimen of the uterus and bladder of a young married woman, aged twenty-nine, affected with scirrhus, in which was seen a large vesico-vaginal fistula. The disease commenced three years ago, after her confinement.

Mr. W. J. Anderson brought forward a

NEW FORM OF PESSARY.

$\mathrm{He}$, in the first instance, alluded to the old boxwood ball pessary, stating its good qualities, and the efficient support it affords in cases of procidentia uteri; and then pointed out some of its imperfections, showing that the cavity of the instrument often becomes filled with the vaginal and uterine discharges, as they do not pass through it, but between its external surface and the internal surface of the vagina; if it fitted firmly enough to prevent this, it must produce injurious pressure, and probably sloughing, if left in long enough. Such being the case, it occurred to him (Mr. Anderson) that an instrument might be made, of the same shape, able to give the same support, but sufficiently elastic to avoid all pain when passing in and out of the vagina, equally light, if not lighter, and incapable either of becoming saturated with the discharges, or of retaining them in its cavity. For this purpose, he showed a permanent air-ball pessary of indiarubber, made by $\mathrm{Mr}$. Clarke, 225, Piccadilly, which was calculated to answer all the good purposes of the other, and avoid all its imperfections, it being light, elastic and firm, filling the vagina, without producing injurious pressure, and beautifully clean, from the fact of its being waterproof even to its string.

Dr. Sieveking then read a paper on some

CASES ILLUSTRATIVE OF SOME POINTS CONNECTED WITH THE PATHOLOGY AND TREATMENT OF EPILEPSY;

and commenced by alluding to the centric and ex-centric nature of the complaint. He did not, however, look upon it as a disease, but as a symptom. Several illustrative cases were then mentioned, and especially one occurring after a mild attack of scarlatina, in which the fits were very severe, and were stopped by the employment of anodynes. A table of cases was next brought forward, to show the predominance of the affection of the left side during the fit. Dr. Sieveking then spoke of the use of the cotyledon umbilicus in the treatment of this affection, and brought forward several cases in proof of its beneficial effects. It was described as producing a slightly sedative and diuretic action, though its exact modus operandi has not yet been discovered; it, however, appeared to him to exercise some control over the disease, and, at the same time, was innocuous to the constitution of the patient.

\section{WESTERN MEDICAL AND SURGICAL SOCIETY} OF LONDON.

Saturday, December 2ND, 1854.

Dr. Barclay, Vice-President, in the Chair.

SEveraL gentlemen were elected members of the Society. Dr. BAnEs then read a paper on DIURETICS, AND THEIR TSES.

After some introductory remarks, he divided diuretics into two classes-the direct and the indirect. The direct were consi- 